\title{
Unidades geomorfológicas de la cuenca del Río Grande de Comitán, Lagos de Montebello, Chiapas-México
}

\author{
Lucy Mora P., Roberto Bonifaz, Rafael López-Martínez
}

\section{Lucy Mora P.}

Imora@geologia.unam.mx

Instituto de Geología, Universidad Nacional Autónoma de México, Ciudad Universitaria, Delegación Coyoacán, C.P. 04510, Ciudad de México, México.

\section{Roberto Bonifaz}

Instituto de Geofísica-UNAM, Universidad Nacional Autónoma de México, Ciudad Universitaria, Delegación Coyoacán, C.P. 04510, Ciudad de México, México.

\section{Rafael López-Martínez}

Instituto de Geología, Universidad Nacional Autónoma de México, Ciudad Universitaria, Delegación Coyoacán, G.P. 04510, Ciudad de México, México.

BOL. SOC. GEOL. MEX. 2016

VOL. 68 NO. 3

P. 377-394

Manuscrito recibido: Julio 3, 2015.

Manuscrito corregido recibido: Enero 22, 2016

Manuscrito aceptado: Febrero 8, 2016

\section{RESUMEN}

La caracterización geomorfológica permite resolver la falta de información geoespacial de una región a diferente escala de observación y a partir de ella, entender las manifestaciones de las formas, procesos y dinámicas de un sistema para diversas aplicaciones en las Ciencias de la Tierra. La cuenca del Río Grande de Comitán-Lagos de Montebello está localizada al sureste del Estado de Chiapas, México, entre la Altiplanicie o Altos de Chiapas, la planicie costera del Golfo y el límite con Guatemala. Es una cuenca kárstica conformada por secuencias sedimentarias de origen marino y transicional cuya distribución estuvo controlada por altos estructurales, y sobre la cual se delimitaron unidades geomorfológicas a escala de $2^{\circ}$ orden, como un antecedente en la comprensión evolutiva y funcional de la misma. Mediante el uso de SIG y con base en el Modelo Digital de Elevación (INEGI), se delimitaron las unidades geomorfológicas, usando criterios morfométricos basados en los parámetros de altitud, pendientes y tipo de relieve, las cuales se discriminaron utilizando criterios de pendiente, altitud y rugosidad por cada unidad geomorfológica.

A partir de este procedimiento automático, se obtuvieron grandes unidades de paisaje (montaña, lomerío y planicie), mismas que se subdividieron subsecuentemente en trece unidades geomorfológicas. La definición de las unidades finales se apoyó en el criterio de experto y trabajo de campo, en donde se identifican diferentes etapas evolutivas y estadios de desarrollo kárstico. Los procesos que controlan la modelación de las formas identificadas son principalmente disolución-erosión y reactivación de zonas antiguamente karstificadas, debido a la dinámica tectónica regional. En ese sentido, el comportamiento de la región puede ser entendido como un desarrollo polifacético con varias etapas de evolución. De esta manera, los primeros alcances de la caracterización de la cuenca permiten definir las unidades que más favorecen el flujo de material por vía superficial, así como las áreas con mayor desarrollo kárstico y por ende mayor dinámica sub superficial.

Palabras clave: geomorfología kárstica, morfometría, Lagos de Montebello, Chiapas, México.

\section{ABSTRACT}

Geomorphological characterization is a tool which can be used for a better understanding of landscape evolution and also to understand the natural dynamics of a system and has broad applications for earth sciences.

The Río Grande de Comitán-Lagos de Montebello watershed is located in the southeastern part of the Mexican state of Chiapas, between the Chiapas central plateau and the Gulf plain, and shares a border with Guatemala. It is a karstic watershed formed by marine and transitional sedimentary sequences, the distribution of which are controlled by tectonic highs, in which second order geomorphological units were defined in order to understand the evolution, function and dynamics of the watershed.

Using a geographic information system and a digital elevation model, the geomorphological units were defined based on morphometric criteria such as height, slope and relief. Later, those units were validated analyzing differences in roughness, slope and elevation for each geomorphological unit.

Using this procedure we defined the main geomorphic areas (mountains, hills and plains). These broad classifications were subdivided into thirteen geomorphological units. The final delineation was supported by expert criteria and field work. Different periods of evolution and different stages of karst development were identified. Processes controlling the geo-forms are principally dissolution-erosion and reactivation of old karst areas due to regional tectonic dynamics. In this sense, the current evolution of the area can be understood as multifaceted with several stages. This first step of the watershed characterization allows defining units related to erosion by surface flow and areas with more karst development, and therefore increased dynamics of the subsurface water.

Keywords: karst geomorphology, morphometry, Lagos de Montebello, Chiapas, Mexico. 


\section{Introducción}

Los paisajes kársticos en México representan aproximadamente un $15 \%$ del territorio nacional. Estos paisajes se localizan principalmente en Tamaulipas, Chiapas y la península de Yucatán (Espinasa-Pereña, 2007) (Figura 1), sin embargo, la caracterización de estos territorios y su funcionamiento tiene aún poco detalle.

El karst es un paisaje que se desarrolla a partir de la disolución de las rocas (caliza, mármol, dolomía, yeso o halita) por la acción del agua principalmente. En este sentido, su evolución y expresiones morfológicas dependerán de las interacciones: roca-agua, condiciones climáticas, topografía y la acción biológica (Ford y Williams, 1989, 2007; Stokes et al., 2010).

Las implicaciones hidrológicas o riesgos ambientales en rocas kársticas radican principalmente en la alta porosidad y permeabilidad que poseen. De esta manera, la alta permeabilidad favorece la transferencia de agua y materia orgánica desde la superficie a las cavidades sub superficiales o viceversa.

El sistema kárstico de los Lagos de Montebello, Chiapas, se considera uno de los escenarios naturales más bellos de México. En él se pueden encontrar una amplia variedad de lagos kársticos que varían en forma, tamaño y tonalidad del agua. Este sistema de lagos cumple una función ecológi-

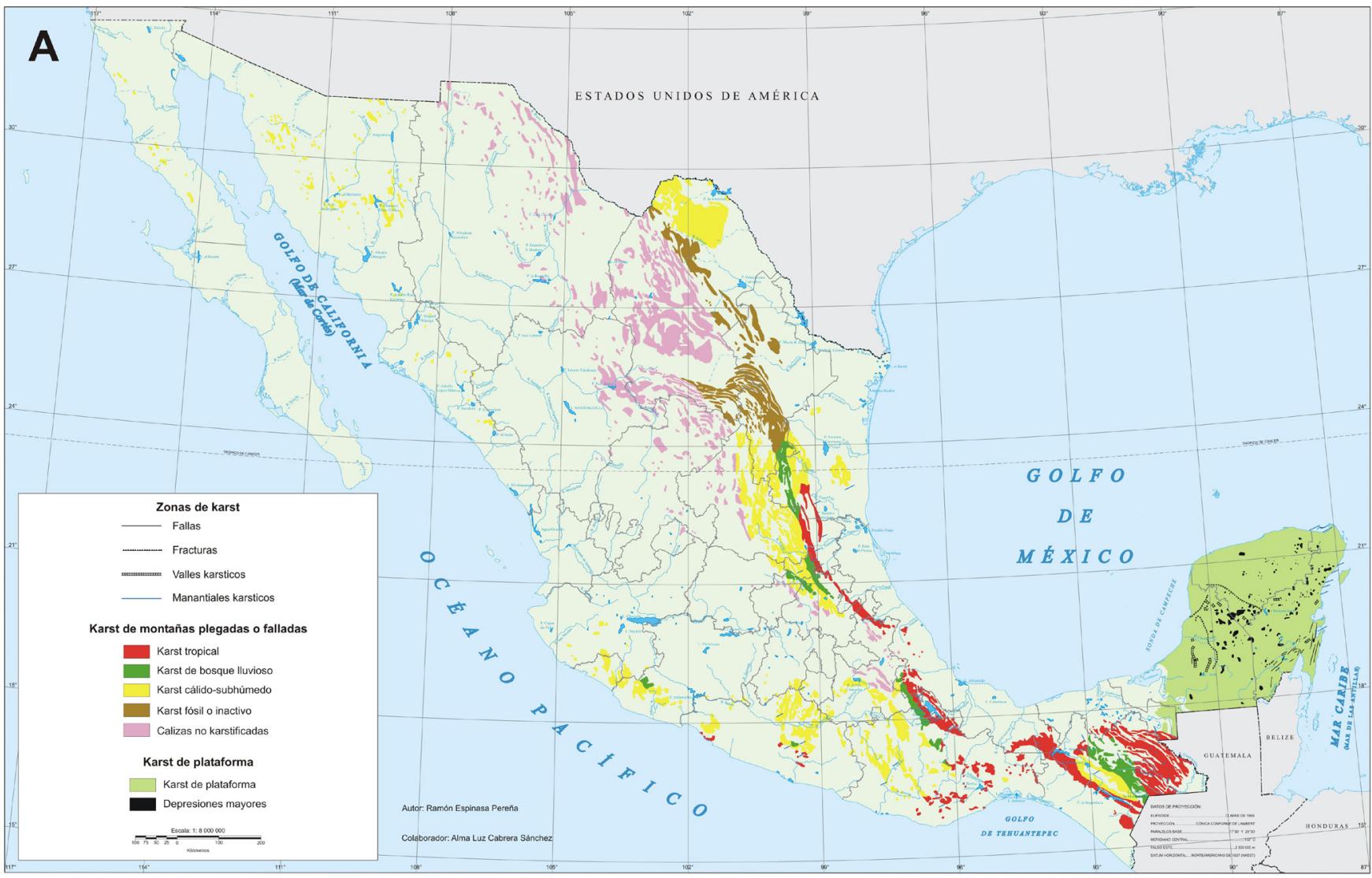


ca de vaso regulador regional, regulador climático y corredor biológico además de servir como fuente de sustento de un número considerable de comunidades que viven de los ingresos generados por el turismo (CONANP-SEMARNAT, 2007).

En las últimas tres décadas este sistema ha soportado múltiples presiones socioeconómicas (IMPLAN Comitán, 2015). El cambio de uso de suelo y como consecuencia la deforestación son algunas de las actividades a las que se le atribuye la modificación de la calidad físico-química del agua de los lagos. Estos cambios son más evidentes en los lagos conectados superficialmente con el sistema hidrológico del Río Grande de Comitán, mostrando fuertes cambios de coloración, burbujeo y olores fétidos. Reportes técnicos mencionan cambio en parámetros como $\mathrm{pH}$, aumento de conductividad eléctrica y altas concentraciones de sulfatos en estos lagos (CFE, 2012).

La evaluación del impacto del cambio de uso de suelo sobre la calidad del agua de los lagos y las propuestas de remediación de los mismos, deben considerar el conocimiento de la dinámica natural del sistema kárstico en toda la cuenca y la identificación de los factores que favorecen o modifican su naturaleza. En este sentido, la caracterización de las unidades geomorfológicas representa una información importante, que además de definir unidades de paisaje y su relación con la evolución de suelos, permite entender el comportamiento hidrológico, el movimiento de nutrientes a través de la escorrentía superficial y la consecuente eutrofización de los cuerpos de agua.

Existen pocos estudios de esta zona, los cuales abordan la descripción del marco geológico regional y muy pocos la morfología y evolución del paisaje. Recientemente Durán et al. (2014), describen a escala semidetallada (1:50000) la geomorfología del parque Nacional Lagunas de Montebello en 17 unidades geomorfológicas, agrupadas en: Endógeno estructural plegado, Exógeno acumulativo, Exógeno denudativo fluvio-kárstico y Exógeno denudativo kárstico. El área del Parque tiene una relativa heterogeneidad morfológica y de origen del relieve, a pesar de la homogeneidad litológica, que se explica por la interacción de los procesos kársticos (exógenos) y tectónicos (endógenos) que tienen lugar en la zona.

Los paisajes kársticos presentan dificultad en la definición de los límites entre las geoformas, debido a la fuerte influencia de los mecanismos de disolución que conllevan a tener límites difusos, además de la gran cantidad de formas caprichosas que se expresan a diferentes escalas. En este sentido, la aplicación de métodos morfométricos permite disminuir las definiciones subjetivas entre ellas.

Zinck (2012) utiliza una de las aproximaciones metodológica basada en criterios morfométricos para definir las formas del terreno. Los parámetros más frecuentemente utilizados incluyen altitud, pendiente, exposición, curvatura y rugosidad del relieve, entre otros. Sin embargo, este tipo de aproximación no informa sobre la génesis de la geoforma, en este sentido los mejores métodos de clasificación son los que llevan a cabo un análisis sistemático de la superficie, describiendo cada componente de forma individual (Hammond, 1964).

Los mapas derivados de esta metodología representan la jerarquía de las formas, en donde se incluyen micro, macro y mega formas, además pueden incluir fases, elementos y paisajes. Dependiendo de los objetivos, los Modelos Digitales de Elevación (MDE) pueden ayudar a ligar las formas con los procesos geomorfológicos (Dikau et al., 1995). De esta manera la clasificación espacial es una herramienta muy poderosa para el análisis de las formas del terreno, definidas en función de su tamaño, orden y complejidad geométrica (Dikau, 1990; Zinck, 2012).

El presente estudio se enfoca en la delimitación de las principales unidades geomorfológicas de la cuenca del Río Grande de Comitán-Lagos de Montebello, mediante la metodología propuesta por Hammond (1964), apoyándose en parámetros morfométricos, de manera que permitan un acercamiento inicial a la comprensión de la diferenciación, evolución del paisaje y los procesos que han 
favorecido el desarrollo del mismo y también un entendimiento del comportamiento hidrológico del sistema lacustre.

\section{2. Área de estudio}

El área de estudio comprende la cuenca del Río Grande de Comitán-Lagos de Montebello. La cuenca (Figura 2), tiene una extensión de 810.43 $\mathrm{km}^{2}$, está comprendida dentro la cuenca del Río Lacantún (INEGI, 2007). Desde el punto de vista hidrológico esta cuenca es parte de la Región Hidrológica No. 30 Grijalva-Usumacinta en la región Sur-Sureste en el estado de Chiapas conocida como la provincia de la Meseta Central (Altiplanicie o Altos de Chiapas) (CFE, 2012).

$\mathrm{Al}$ final de la cuenca, se localiza el área natural protegida con carácter de Parque Nacional "Lagunas de Montebello", decretado el 16 de Diciem- bre de 1959, con una extensión de 63.96 km² y es considerada una Región Terrestre prioritaria para la conservación (CONANP-SEMARNAT, 2007). La cuenca del Río Grande de Comitán está conformada por el afluente principal Río Grande, el cual es alimentado por el lago Juznajab, ubicado en la parte alta de la cuenca. El Río Grande recorre zonas urbanas y agrícolas, hasta desembocar en el sistema Lagos de Montebello (Figura 2) constituido por más de cincuenta lagos de origen kárstico (CONANP-SEMARNAT, 2007). La alimentación de la zona lacustre es principalmente subterránea generando un sistema de dolinas y otras formas originadas por la disolución de las rocas calizas (Vázquez y Méndez, 1994).

La cuenca pertenece a lo que Ortega-Gutiérrez et al. (1992) denominaron como provincia geológica de Falla de Transcurrencia del cinturón Chiapaneco de Pliegues y Fallas. Fisiográficamente, éstas pertenecen a la provincia denominada Tierras
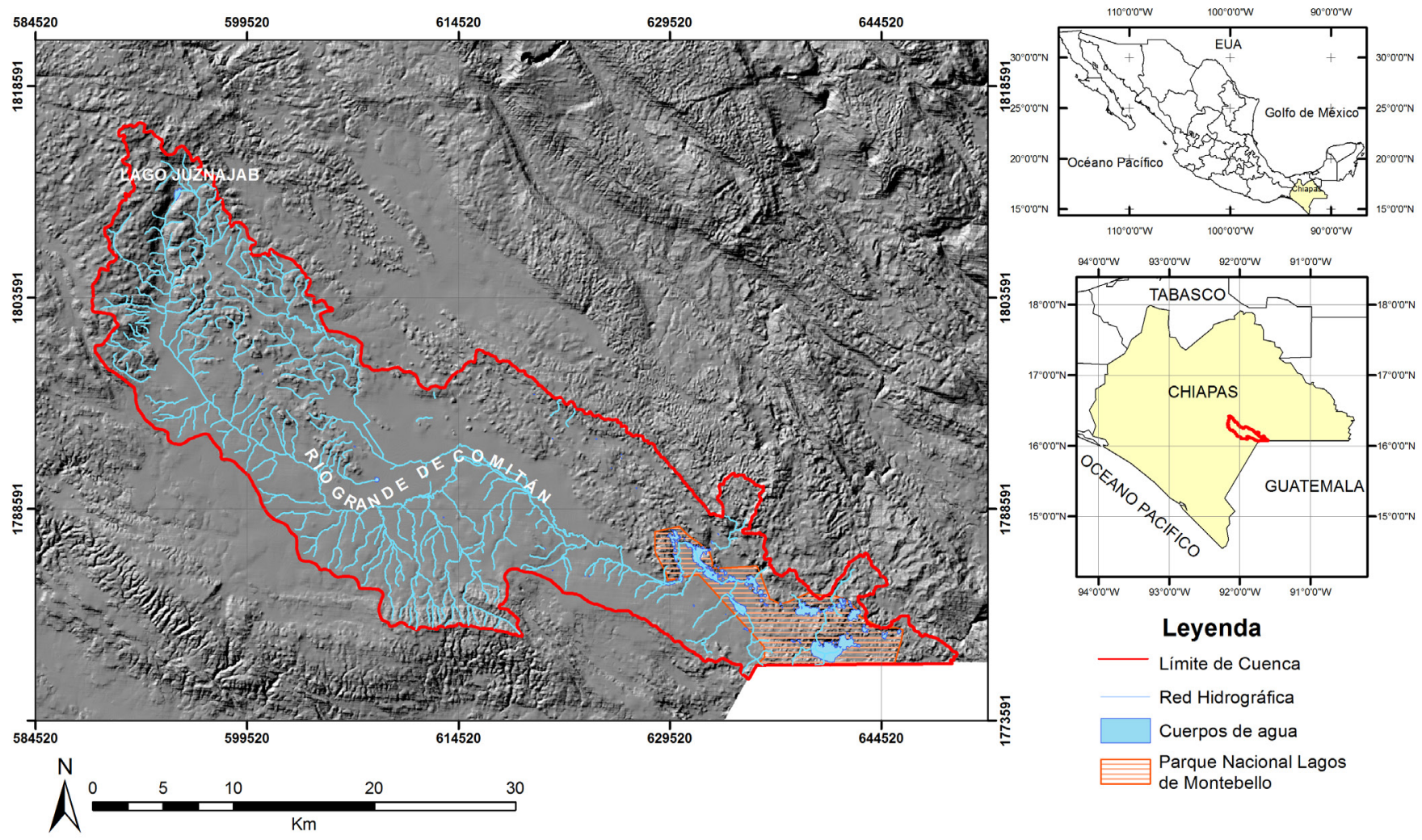
Altas de Chiapas-Guatemala (Servicio Geológico Mexicano, 2013 cartas E-15 D-73, E15 D-84 y E15 D-83 escala 1:250000).

\subsection{GEOLOGÍA DEL ÁREA}

La información geológica del área de estudio reportada en trabajos previos tiene poco nivel de detalle. Varias de las formaciones geológicas se encuentran en estado de nomenclatura informal y los mapas geológicos no hacen distinción entre algunas de ellas, por lo que no es posible hacer una clara diferenciación de las mismas. En el área afloran cuatro unidades litoestratigráficas fundamentales:

- Grupo Sierra Madre. Nuttal y Hegwein, 1929 en (Salas, 1949) se refirieron a las calizas, en este lugar, como Calizas Sierra Madre. Actualmente se considera como Grupo, incluyendo a las formaciones Cantelhá, Jolpabuchil y Cintalapa (Quezada-Muñetón, 1987). En el área de estudio, el Grupo varía en edad del Aptiano al Santoniano, sin reportar diferencia entre las formaciones que lo comprenden. Está compuesto fundamentalmente por calizas, parcial o totalmente dolomitizadas, de diferentes ambientes de depósito.

- Formaciones Ocozocuautla y Angostura. Según el Léxico Estrtigráfico Mexicano, ambas formaciones están indiferenciadas a escala 1:250000 y están compuestas mayormente por calizas y lutitas del Campaniano- Maastrichtiano.

- Depósitos Pleistocénicos. Estos depósitos no poseen una nomenclatura estratigráfica establecida. En el área están representados por depósitos tipo conglomerado polimíctico, yeso y limolita (Léxico Estratigráfico Mexicano).

- Aluviones del Cuaternario. Se encuentran representados por aluviones depositados en los lechos de los ríos (Léxico Estratigráfico Mexicano).

Estructuralmente el área se encuentra ubicada dentro del cinturón Chiapaneco de Pliegues y Cabalgaduras (Ortega-Gutiérrez et al., 1992; Durán et al., 2014) cuya tectónica está estrechamente relacionada con la interacción entre las placas de
Cocos, Norteamérica y Caribe (Guzman-Speziale y Meneses-Rocha, 2000). Esta región ha estado sujeta a diversos procesos geológicos como son la sedimentación, plegamiento y fallamiento $(\mathrm{Pa}-$ dilla-Sánchez, 2007; Arellano-Contreras y Jiménez-Salgado, 2011). Todos estos eventos actuaron en diferentes periodos con distintas direcciones de esfuerzos y generaron el estilo de deformación que conforma el marco tectónico-estructural actual de la región en la que se encuentra el Parque Nacional Lagunas de Montebello. Los planos axiales de los pliegues principales tienen un rumbo NW y es coincidente con el rumbo de las principales fallas normales.

\subsection{CLIMA}

La CFE (2012), reporta medidas de temperatura y precipitación en un conjunto de estaciones regionales del área de Montebello, Chiapas. Se observa que las temperaturas medias no presentan cambios significativos entre sí, situándose alrededor de $17.5^{\circ} \mathrm{C}$. En promedio la época más calurosa del año se registra entre los meses de mayo a octubre. Por otro lado, la precipitación media anual es de 1482.6 mm, y se observa en la Figura 3 que no hay una distribución uniforme de la precipitación, puesto que los valores varían de un mínimo de $895.1 \mathrm{~mm}$ hasta un valor máximo de $2587.9 \mathrm{~mm}$. Los meses más lluviosos son de junio a septiembre, este último es el mes con los máximos valores de precipitación, por lo cual la mayor precipitación ocurre en verano.

\section{Metodología}

La metodología se implementó en un Sistema de Información Geográfica (ArcGIS 10.1), utilizando como fuente de entrada un modelo digital de elevación (DEM). El DEM utilizado corresponde al continuo de elevaciones mexicano versión 3.0, descargado del sitio Web del INEGI con una resolución de 15 m x 15 m y un error medio cuadrático de 4.9 m. Para la generación del modelo, se 


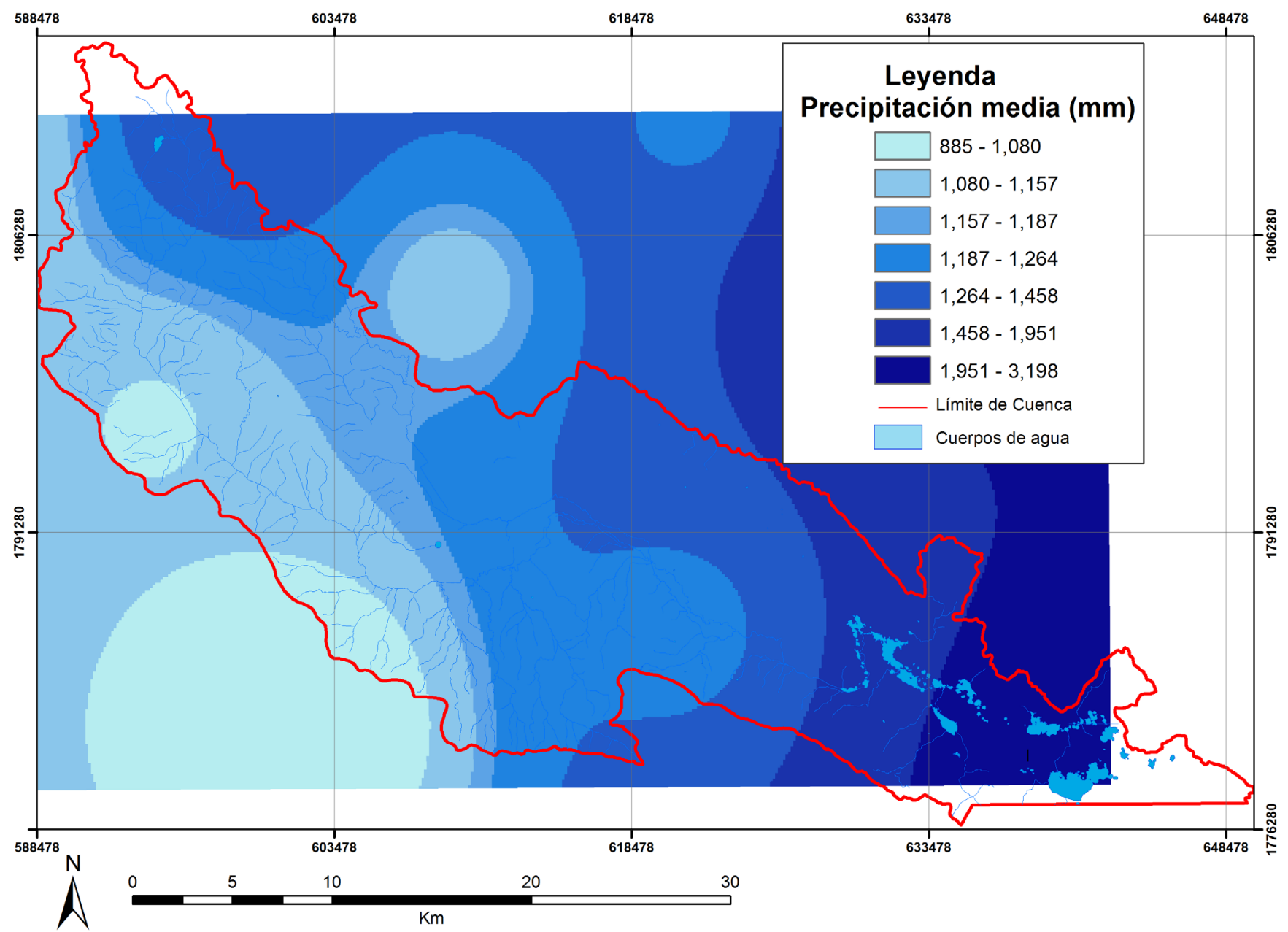

Figura 3 Mapa de la distribución de la precipitación media anual a partir de la interpolación de datos de las estaciones climatológicas (CFE 2012). En general se observa que los valores de precipitación media aumentan hacia los Lagos de Montebello.

utilizaron diversos tipos de información fuente y un modelo de interpolación robusto denominado ANUDEM (INEGI, 2013).

La primera gran definición de las unidades se logró mediante el uso de la metodología de Hammond (1964). De acuerdo a Gallant et al. (2005) se usaron diferentes radios de búsqueda (cálculo de estadísticas focales) para crear los parámetros de pendiente, relieve y perfiles. Por ejemplo, en el cálculo de la pendiente se aplicó el algoritmo propio implementado en el SIG y posteriormente se reclasificó en rangos de pendiente. En un siguiente paso se calculó el porcentaje ocupado por cada rango de pendiente en el espacio. De la misma manera, se llevó a cabo el mismo procedimiento para las variables relieve y perfil, obteniéndose porcenta- jes del terreno cubiertos por cada variable. Con estos tres elementos se puede identificar el área de pendientes moderadas en elevaciones bajas o pendientes moderadas en elevaciones altas, entre otros casos. Esto resulta en una aplicación automática de una serie de operaciones en el SIG que incluyen los cálculos, reclasificaciones, máscaras binarias, suma de mapas, etc., cuyo resultado son las grandes categorías de Hammond (planicies, planicies suaves, planicies con lomeríos, planicies con relieve considerable, planicies con montañas altas y mesetas con relieve moderado) que son resultado de la expresión morfométrica del relieve.

Dado que el resultado de este procedimiento es de grandes unidades, los detalles finos de diferenciación y algunos límites de unidades se realizaron 
por medio del criterio de experto y verificación de campo, considerándose el sustrato geológico, las expresiones morfológicas superficiales y los procesos genéticos para obtener las geoformas finales. Para calificar las formas, se estimó además las elevaciones, la pendiente, la geología y rugosidad mediante una ventana móvil que calcula la desviación estándar de la pendiente (Figura 4).

\section{Resultados}

El mapa geomorfológico a escala de la cuenca permitió distinguir trece unidades geomorfológicas, asociadas a diferente litología y procesos genéticos, las cuales se describen desde las unidades de montaña hacia las zonas de planicie (Figura 5). También se presentan las características morfométricas que permitieron discriminar las áreas, ordenadas con base en los valores de rugosidad de mayor a menor (Tabla 1).

\section{Elevaciones bajas con karst de dolinas y} poljés inundados: Esta unidad se ubica al Sureste de la Cuenca, donde se localizan gran parte de los lagos (Figura 6). Durán et al. (2014) denominan esta zona como "lagos de montaña" ya que están a mayor altura en relación con los otros lagos. Esta unidad cubre una extensión de $60.8 \mathrm{~km}^{2}$ y está desarrollada sobre calizas y dolomías del Cretácico.
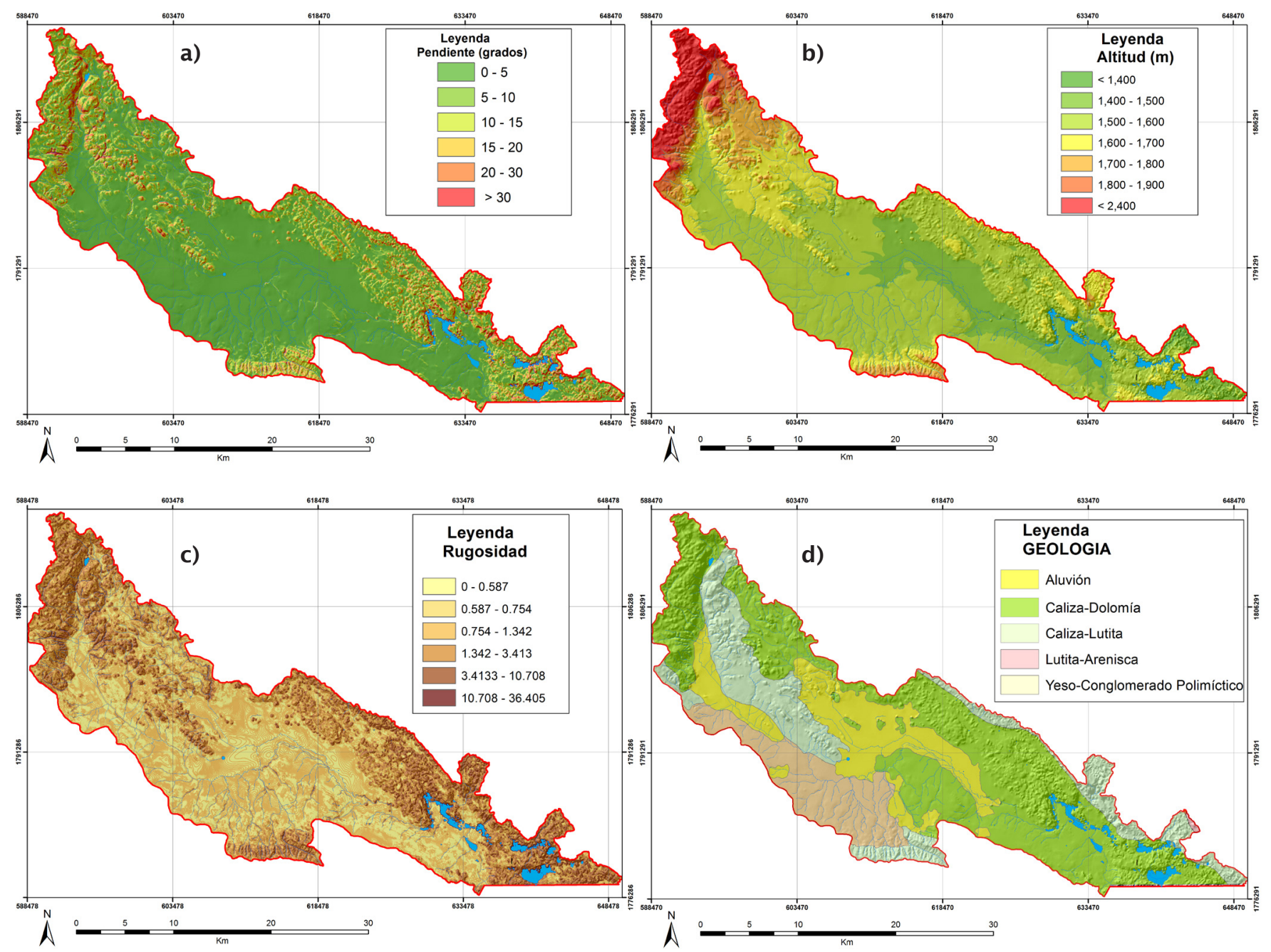

Figura 4 Mapas temáticos generados para desarrollar la metodología. (a) Mapa de pendiente, (b) Mapa altitudinal, (c) Mapa de rugosidad y (d) Mapa geológico. 


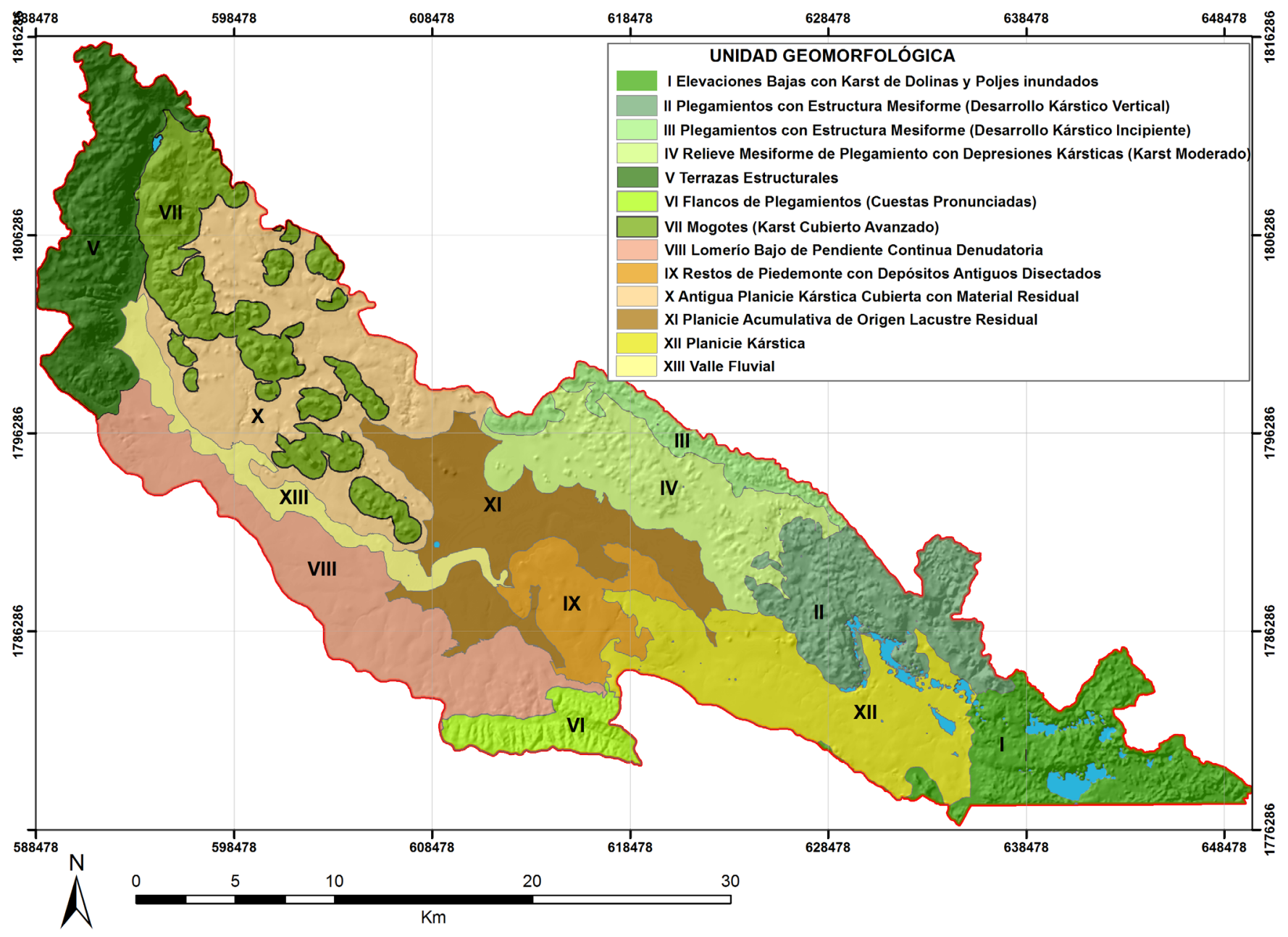

Figura 5 Delimitación de las trece unidades geomorfológicas de la cuenca del Río Grande de Comitán-Lagos de Montebello, Chiapas.

La altura promedio es $1522 \mathrm{msnm}$, pendientes máximas de $57.5^{\circ}$ y se estima una rugosidad máxima de 18.6 (Tabla 1), en esta zona no se identifica ninguna red de drenaje superficial, característica típica de este tipo de paisaje kárstico. Su morfología se puede asociar a un intenso desarrollo de los procesos kársticos, unido a la existencia de un nivel de base cercano a las dolinas y otras formas kársticas. Dominan, las dolinas y poljes irregulares con paredes escarpadas de gran tamaño. Su forma va desde morfologías de contorno redondeado hasta elíptico, permaneciendo inundada la mayor parte de estas formas. La presencia de campos de dolinas y la coalescencia de las mismas en forma de

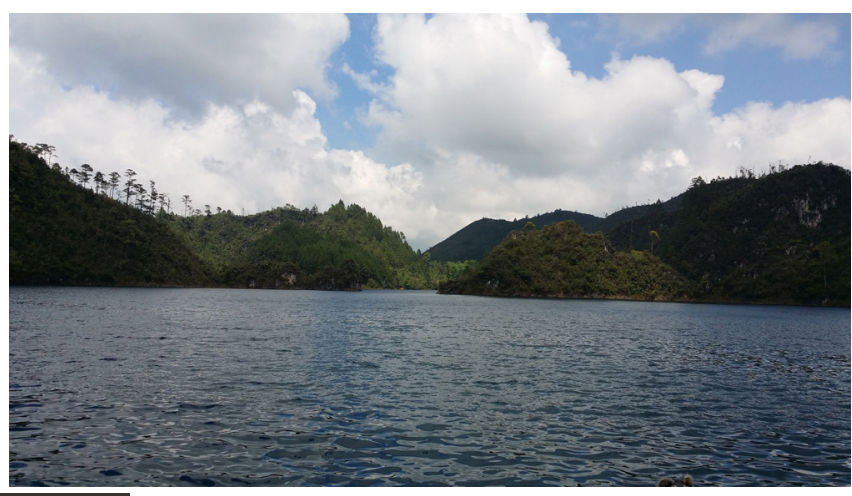

Figura 6 Ejemplo de la unidad I, una vista al NE de los lagos de Montebello que representan las elevaciones bajas con karst de dolinas y poljes inundados. 
Tabla 1. Características morfométricas de las unidades Geomorfológicas.

\begin{tabular}{|c|c|c|c|c|c|c|c|c|c|}
\hline \multirow{2}{*}{ 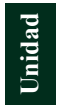 } & \multirow{2}{*}{ Unidad Geomorfológica } & \multirow{2}{*}{ Litología } & \multicolumn{2}{|c|}{$\operatorname{AREA}\left(\mathrm{km}^{2}\right)$} & \multicolumn{2}{|c|}{ ALTURAS (m.s.n.m) } & \multicolumn{2}{|c|}{ PENDIENTE $\left({ }^{\circ}\right)$} & \multirow{2}{*}{$\begin{array}{c}\text { RUGOSIDAD } \\
\text { prom. }\end{array}$} \\
\hline & & & prom. & desv & prom. & desv & prom. & desv & \\
\hline \multirow{6}{*}{ 营 } & $\begin{array}{l}\text { I-Elevaciones Bajas con Karst de Dolinas y Poljés } \\
\text { inundados }\end{array}$ & Caliza-dolomía & 60.86 & 0.17 & 1522.8 & 61.4 & 11.3 & 8.3 & 2.9 \\
\hline & $\begin{array}{l}\text { II-Plegamientos con Estructura Mesiforme (Desarrollo } \\
\text { Kárstico Vertical) }\end{array}$ & Caliza-dolomía & 61.74 & 0.01 & 1571.4 & 64.8 & 11.6 & 8.2 & 2.7 \\
\hline & $\begin{array}{l}\text { III-Plegamientos con Estructura Mesiforme (Desarrollo } \\
\text { Kárstico Incipiente) }\end{array}$ & Caliza-dolomía & 22.93 & 0.01 & 1577.8 & 45.3 & 9.2 & 6.4 & 2.2 \\
\hline & $\begin{array}{l}\text { IV-Relieve Mesiforme de Plegamiento con Depresiones } \\
\text { Kársticas (Karst Moderado) }\end{array}$ & Caliza-dolomía & 69.47 & 0 & 1529.3 & 36.3 & 5.2 & 5.1 & 1.2 \\
\hline & V-Terrazas Estructurales & Caliza-dolomía & 70.64 & 0.05 & 1946.8 & 206.9 & 11.5 & 7.2 & 2.1 \\
\hline & VI-Flancos de Plegamientos (Cuestas Pronunciadas) & Caliza-Lutita & 21.51 & 0.01 & 1692.8 & 69.3 & 11.1 & 5.9 & 2.1 \\
\hline \multirow{3}{*}{ : } & VII-Mogotes (Karst Cubierto Avanzado) & Caliza-Lutita & 73.93 & 0.01 & 1700.7 & 99.1 & 9.4 & 6.8 & 1.9 \\
\hline & VIII-Lomerío Bajo de Pendiente Continua Denudatoria & $\begin{array}{l}\text { Conglomerado } \\
\text { polimíctico }\end{array}$ & 90.44 & 0 & 1562.3 & 24.7 & 1.8 & 1.6 & 0.3 \\
\hline & $\begin{array}{l}\text { IX-Restos de Piedemonte con Depósitos Antiguos } \\
\text { Disectados }\end{array}$ & Caliza-dolomía & 34.12 & 0 & 1525.7 & 23.7 & 1.5 & 1.3 & 0.3 \\
\hline \multirow{4}{*}{$\begin{array}{l}\frac{0}{0} \\
\frac{\pi}{\pi} \\
\frac{\pi}{2}\end{array}$} & $\begin{array}{l}\text { X-Antigua Planicie Kárstica Cubierta con Material } \\
\text { Residual }\end{array}$ & Caliza-dolomía & 103.73 & 0.01 & 1622.1 & 67.5 & 4.1 & 3.7 & 0.9 \\
\hline & XI-Planicie Acumulativa de Origen Lacustre Residual & Aluvión & 76.31 & 0.01 & 1503.7 & 14.4 & 0.6 & 0.9 & 0.2 \\
\hline & XII-Planicie Kárstica & Caliza-dolomía & 85.73 & 0.01 & 1505 & 34.6 & 2.3 & 2.3 & 0.4 \\
\hline & XIII-Valle Fluvial & Caliza-Lutita & 28.01 & 0 & 1541.5 & 19.1 & 1.2 & 1 & 0.2 \\
\hline
\end{tabular}

uvalas y poljés, manifiestan el desarrollo kárstico avanzado así como un control estructural inicial.

II. Plegamientos con Estructura Mesiforme (Desarrollo Kárstico Vertical): Esta unidad se localiza al norte de los lagos, denominados por Durán et al. (2014) como "lagos de planicie" y cubre un área de $60.4 \mathrm{~km}^{2}$. Se desarrollan principalmente sobre calizas y dolomías, alcanzan alturas promedio de 1551 msnm con pendientes máximas de $48.9^{\circ}$ y una rugosidad máxima de 14.6. Al igual que la anterior unidad no presenta red de drenaje superficial (Tabla 1). A escala de detalle Durán et al. (2013) mencionan que estos plegamientos son laderas montañosas del Paleógeno y su génesis está relacionada con procesos endógenos estructurales, asociados a las fallas tectónicas regionales. Esta puede ser la razón por la cual su característica principal es la presencia de paredes verticales que se expresa en una alta rugosidad (Figura $7 \mathrm{a}$ y $7 \mathrm{~b}$ ).

III. Plegamiento con estructura Mesiforme (Desarrollo Kárstico Incipiente): Correspon- de a bloques de calizas y lutitas que ocupan un área de $22.9 \mathrm{~km}^{2}$ en la parte norte- centro de la Cuenca. Esta unidad tiene alturas máximas de 1706.9 msnm, pendientes máximas de $37.2^{\circ}$, mientras que la rugosidad máxima es de 9.6. Al igual que las unidades anteriores no presenta red de drenaje superficial (Tabla 1). Particularmente, este relieve mesiforme es controlado por elevaciones aisladas, formadas por levantamientos del Plioceno-Pleistoceno con estructuras plegadas, que favorecen la erosión en dirección de los escurrimientos. Sin embargo, los procesos de disolución kárstica se expresan de manera incipiente. Esta geoforma coincide con una pequeña franja de calizas y lutitas que se encuentra casi en el borde de la cuenca (Figuras 7c). Al ser las lutitas muy impermeables y con un bajo grado de solubilidad, éstas actúan como pantallas que no limitan la circulación del agua hacia conductos subterráneos y generan niveles de base locales. Estas características propias de la interacción agua-roca provocan que los procesos kársticos 


\section{a}
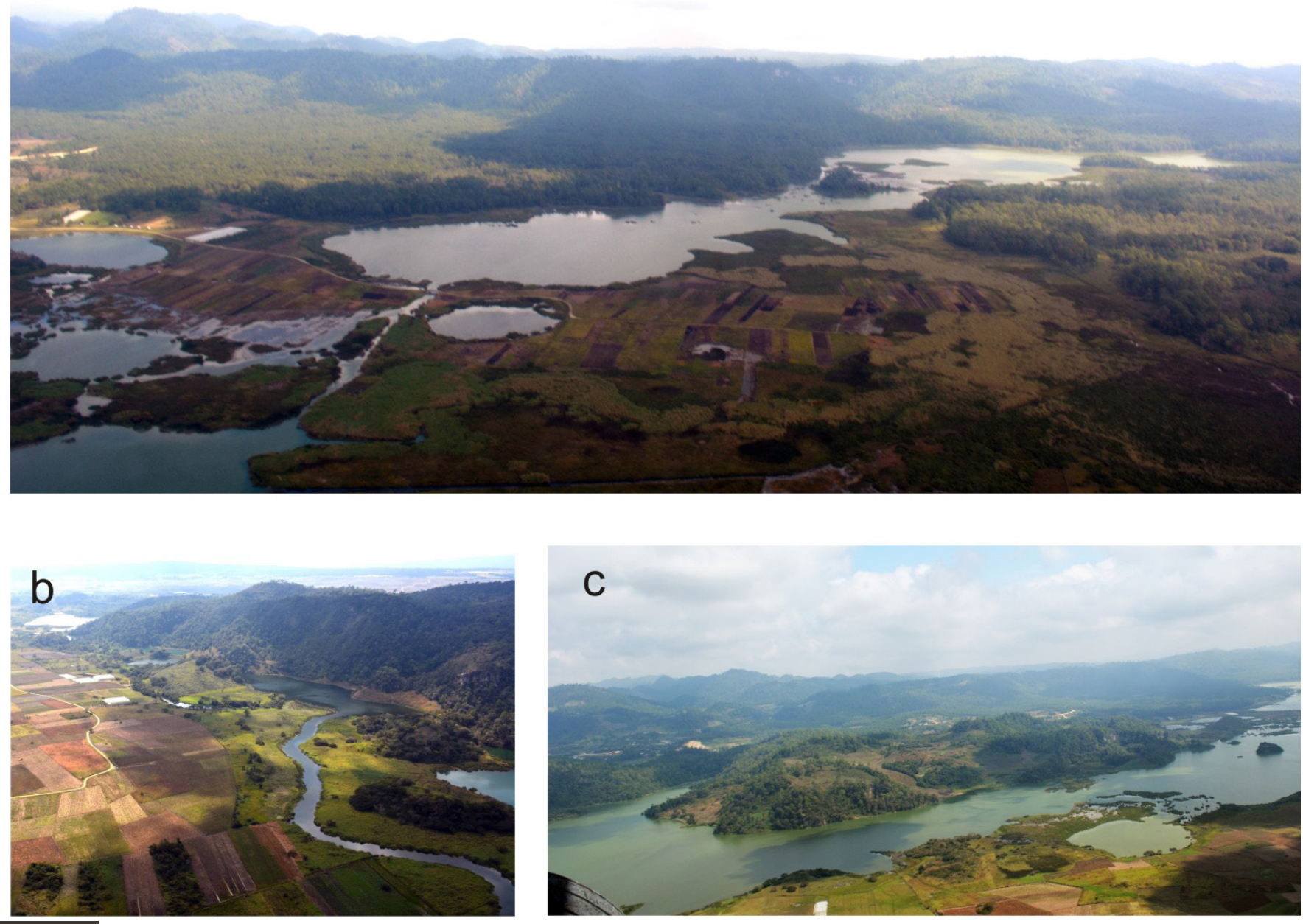

Figura 7 Fotografías que representan las unidades II y III de plegamiento con estructura mesiforme. (a) Ejemplo que muestra la planicie kárstica en el primer plano y las montañas del fondo que representan las unidades de karst moderado e incipiente (Unidades II y III), (b) Ejemplo del desarrollo kárstico vertical con pendiente pronunciada y paredes verticales, rodeada por la planicie kárstica y

(c) Fotografía aérea donde se observa la unidad de karst incipiente.

sean reducidos en comparación con otras geoformas presentes en la cuenca, siendo superados por los procesos de erosión.

IV. Relieve Mesiforme de Plegamiento con Depresiones Kársticas (Desarrollo Kárstico Moderado): Esta unidad está localizada en la zona norte de la cuenca cubriendo un área de $67.94 \mathrm{~km}^{2}$. La altura máxima es de $1646.7 \mathrm{msnm}$, las pendientes entre 0 y $32^{\circ}$ y los valores de rugosidad son bajos (máximo 9.2 (Tabla 1). Las litologías dominantes son calizas y dolomías.

Esta unidad se distingue por un relieve bajo, alter- nando depresiones kársticas y colinas residuales, actuando fundamentalmente procesos de denudación de baja energía en una zona kárstica cercana al nivel de base local.

V. Terrazas Estructurales: Se localiza al Noroeste de la cuenca y ocupa un área de $70.64 \mathrm{~km}^{2}$. Corresponde a la unidad con mayores alturas, con un promedio de $1946.8 \mathrm{msnm}$. Las litologías predominantes son calizas y dolomías. La morfología de esta unidad refleja un fuerte control estructural evidenciado por la presencia de una red de drenaje con cauces rectos y cambios bruscos de dirección 
y facetas triangulares. Presenta erosión diferencial, pliegues suaves y simétricos en dirección del anticlinal (Figura 8). Se observan rasgos erosivos que coinciden con la fuerte pendiente (máxima 48.8 ${ }^{\circ}$ ) (Tabla 1).

Esta unidad posee valores altos de rugosidad (máxima 15.5) debido a la alta densidad de la red de drenaje. Estos valores indican que los procesos de erosión dominan sobre los procesos de disolución y coincide con las zonas de menor precipitación. La presencia de abundantes facetas triangulares y la aparición de ríos con valles en $\mathrm{V}$ sugieren una reactivación de esta área que parece coincidir con algunos lineamientos casi N-S. Sin embargo, es necesario realizar estudios detallados para deter- minar la evolución neotectónica del área.

VI. Flancos de Plegamiento (Guestas pronunciadas): La unidad se ubica en el borde centro-sur de la cuenca y ocupa un área de $21.57 \mathrm{~km}^{2}$. La altura promedio es $1692.8 \mathrm{msnm}$ y la pendiente máxima es de $40.4^{\circ}$ (Tabla 1). Posee una alta densidad de la red de drenaje que afecta de manera directa a los valores de rugosidad (12.7), indicando que los procesos de erosión dominan sobre los de disolución.

En esta unidad abundan cauces rectos con valles en forma de $\mathrm{V}$, desarrollados sobre fallas, típico de ríos muy activos. Su litología está conformada por calizas y lutitas del Campaniano-Maastrichtiano que facilitan los procesos erosivos. Presenta mor-
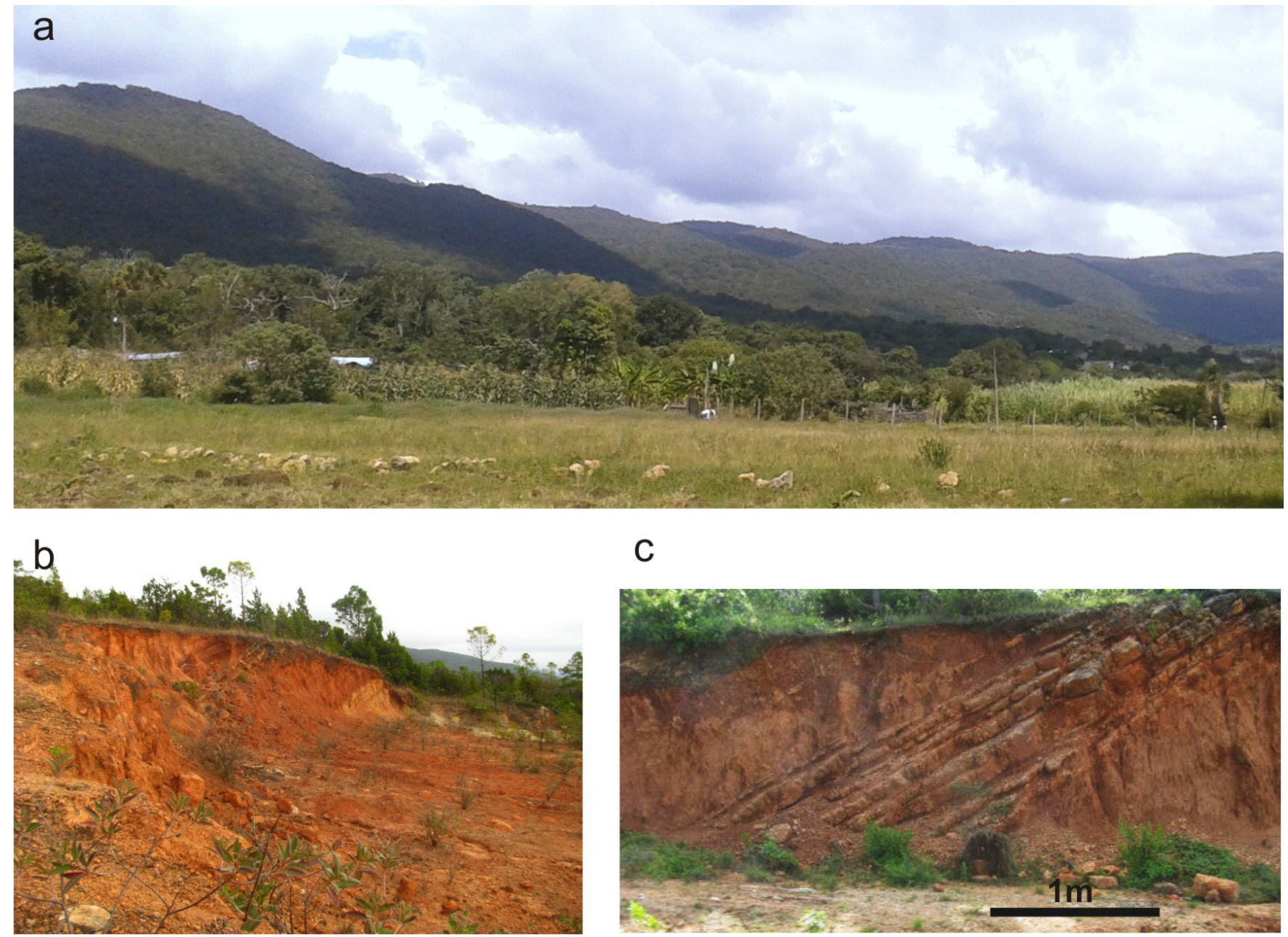

C

Figura 8 (a) Fotografía panorámica hacia el NO de la unidad V de terrazas estructurales, en donde se observan las pendientes pronunciadas (b) Se aprecia el material calcáreo y poco desarrollo de suelo (c) En este corte sobre la carretera se aprecia los pliegues en dirección N-S. 
fología escarpada aparentando una zona de joven reactivación o basculamiento.

\section{Mogotes Relícticos o Karst Relíctico:}

Corresponde morfológicamente a estructuras redondeadas aisladas en una llanura aluvial-fluvial, de alturas no mayores a $50 \mathrm{~m}$ y pendiente máxima de $42.2^{\circ}$ (Tabla 1). La unidad se localiza en las partes altas a $1700 \mathrm{msnm}$, inmersa en una zona de planicie, como relictos de bloques de caliza y lutita (Figura 9). La rugosidad presenta valores relativamente altos (1.3) (Tabla 1) asociados a procesos de disolución y formación de colinas residuales. La existencia de estas formas de karst relíctico evidencia una fuerte y continuada karstificación durante periodos largos. Se observa un karst maduro en el que la disolución ha llegado al nivel de base regional y por ende los procesos de disolución vertical han dado pie a procesos de disolución y expansión horizontal. Su composición litológica (calizas y lutitas) favorece la existencia de formas redondeadas tipo mogote sin que se hayan detectado hasta el momento otras formas como karst de torre.

VIII. Lomerío Bajo de Pendiente Continua y Denudatoria: Esta unidad se localiza al suroeste de la cuenca y ocupa un área de $90.44 \mathrm{~km}^{2}$. A diferencia de las demás unidades, la litología varía entre conglomerados polimícticos y yesos. Esta diferencia litológica se expresa en formas de pendiente suave casi planas (máxima $22.2^{\circ}$ ) y rugosidad baja de 5.5 (Tabla 1).

Esta unidad se caracteriza por presentar fuertes evidencias erosivas expresadas a través de cárcavas profundas que están fuertemente disectadas por eventos fluviales anteriores. No se observan rasgos
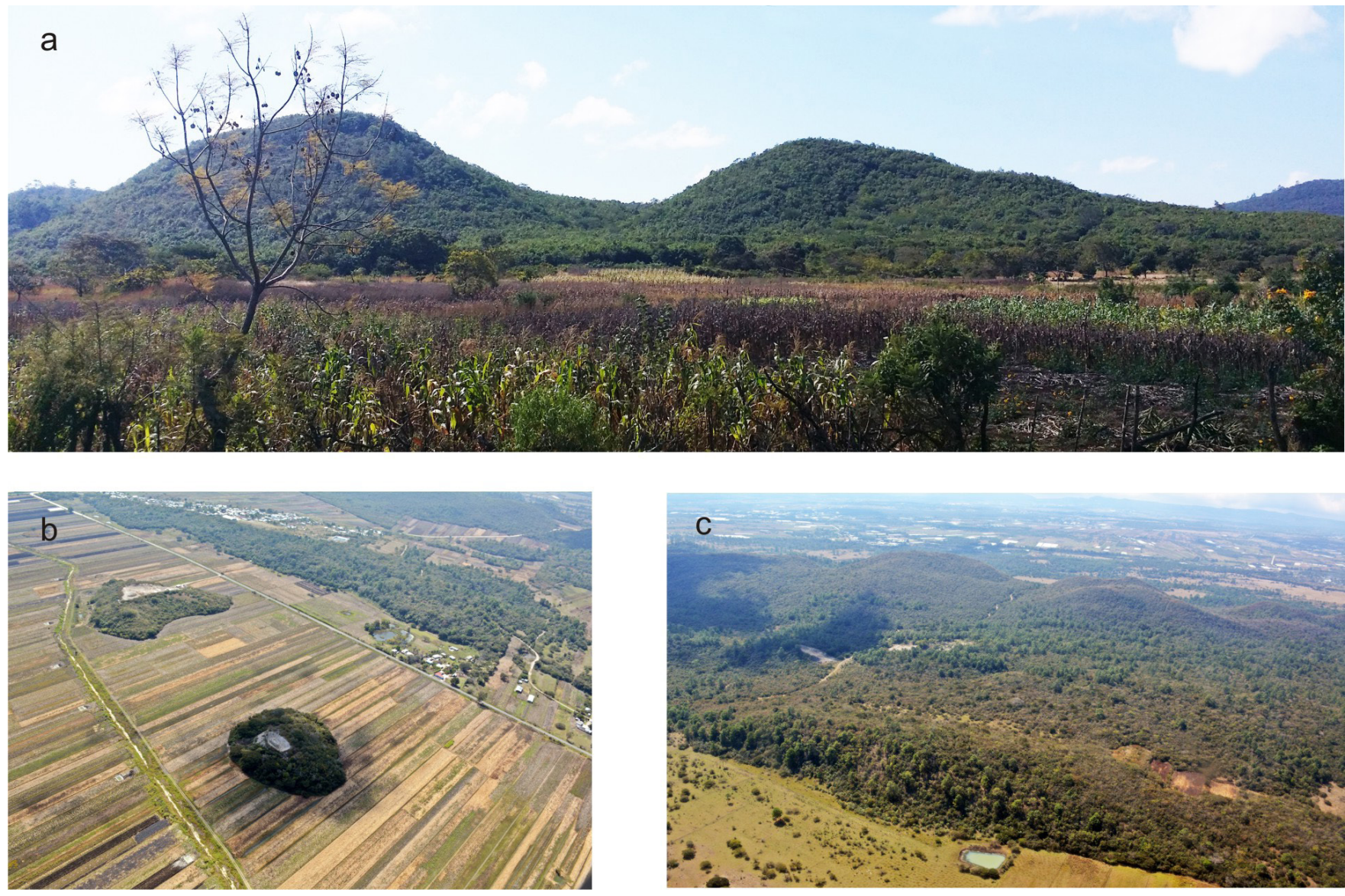

Figura 9 (a) Fotografía panorámica de la zona de Mogotes relícticos, vista al E donde se observa al fondo la morfología redondeada de los mogotes inmersos en la Planicie kárstica antigua cubierta con material residual (b) Ejemplo de Mogotes aislados dentro del material residual de la unidad X (c) Otro ejemplo de Mogotes cubiertos de vegetación natural vista al SE. 
de disolución, sin embargo, el alto grado de redondez de los clastos del conglomerado acuña la idea de que la zona estuvo expuesta a eventos fluviales antiguos. Actualmente, se observa una amplia red de drenaje y escasa vegetación como expresión de dinámicas erosivas intensas, que favorecen el traslado y movimiento rápido de flujos hacia la base de la cuenca.

IX. Restos de Piedemonte con Depósitos Antiguos Disectados: Esta unidad se localiza en la parte sur-centro de la cuenca y ocupa un área de $34.12 \mathrm{~km}^{2}$. Corresponde litológicamente a materiales deformados por calizas y dolomías, con pendientes muy suaves (máximo $19.2^{\circ}$ ) y rugosidad baja de 6 (Tabla 1).

Esta geoforma es el resultado de la re-modelación de crestas pronunciadas de flancos de plegamientos por la acción erosiva y el aporte de sedimentos aluviales, coluviales y fluviales (Figura 10). Adicionalmente presenta abundantes sedimentos retrabajados que al parecer están ligados a antiguos procesos fluviales y aluviales generados fuera de la cuenca. Estos sedimentos pueden estar relacionados a la zona montañosa que se encuentra al sur de la cuenca, sin embargo, es necesario profundi-

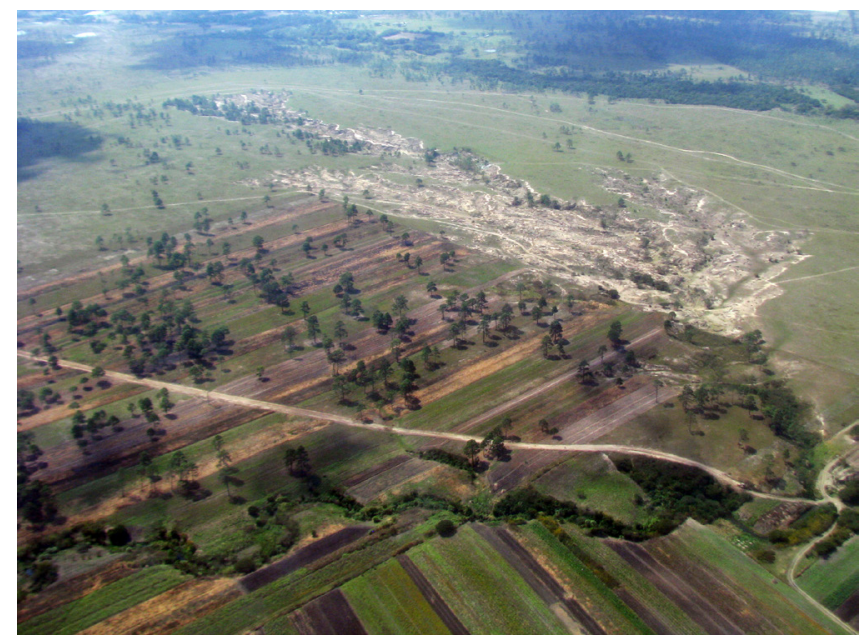

Figura 10 Vista aérea de la unidad de Restos de piedemonte con depósitos antiguos disectados, donde se observan las cárcavas que ocupan amplias áreas de la unidad IX, como expresión de procesos erosivos avanzados favorecidos por el cambio de uso de suelo. zar en la sedimentología de esta geoforma para determinar las posibles áreas de origen.

\section{Planicie Kárstica Antigua Gubierta con}

Material Residual: Esta unidad se localiza al noroeste de la cuenca, rodeando la unidad de Mogotes relícticos (Figura 9). Se encuentra emplazada sobre litologías que varían entre calizas, dolomías y lutitas rellenas de material residual. Presenta una rugosidad muy baja (0.9) y una morfología alargada rumbo de NW (Tabla 1). Características típicas de una llanura de corrosión de nivel de base con colinas y mogotes relícticos. La presencia de estas llanuras rellenas de material residual es la expresión de largos y continuos procesos de disolución que han alcanzado el nivel de base regional. Una vez que este nivel de base es alcanzado, se extiende el crecimiento horizontal de la geoforma formando extensas llanuras que son rellenadas por el material residual y por la formación de suelos. Esta geoforma está genéticamente relacionada con los mogotes relícticos.

XI. Planicie Acumulativa de Origen Lacustre Residual: Esta unidad se localiza en la parte central de la cuenca y abarca un área de 76.31 $\mathrm{km}^{2}$. Es una unidad topográficamente plana en la zona más baja de altura promedio de 1503 msnm y rugosidad muy baja (0.2) (Tabla 1) (Figura 11). Una hipótesis de su génesis está relacionada con la presencia de un antiguo lago, que fue desecado por el cambio de nivel freático de la zona, a razón de probables levantamientos tectónicos o cambios climáticos regionales y que posteriormente, el área fue rellenada de material residual, producto de procesos de depósito. En el perfil de suelo que se presenta en la Figura 11, se aprecian dos capas, la parte superficial es un material muy arcilloso y que a profundidad de $70 \mathrm{~cm}$ se enriquece en limos hasta un 60 \% (Martínez, 2015) y además se encuentra por debajo del nivel de base local.

XII. Planicie Kárstica: Esta unidad abarca el área de los "lagos de planicie" (Durán et al., 2014) hasta casi el centro de la cuenca, representando un área de $85.7 \mathrm{~km}^{2}$, con pendiente muy bajas $\left(2.3^{\circ}\right)$ (Tabla 1). Sus principales agentes modeladores son 

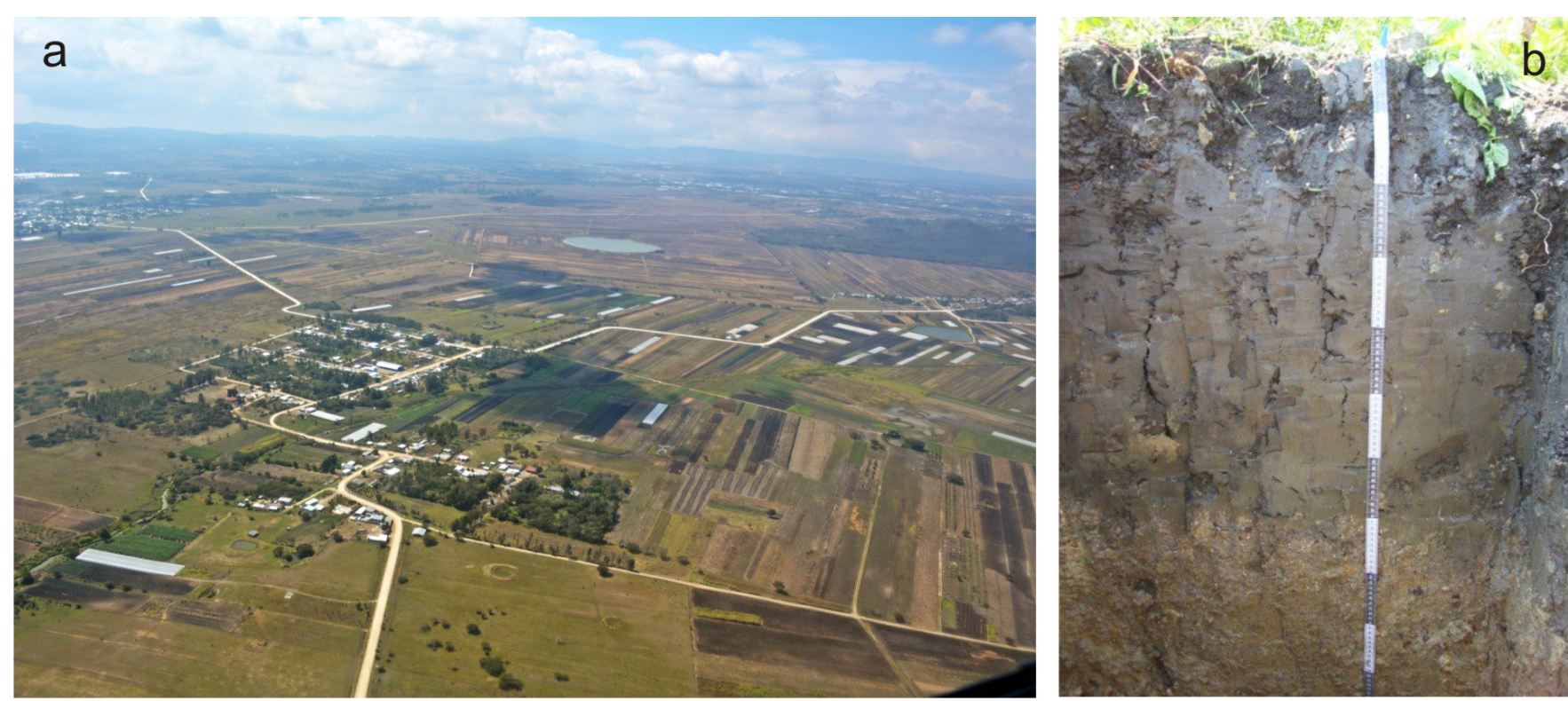

Figura 11 (a) Ejemplo de la Planicie acumulativa de origen lacustre residual Unidad XI, vista al SE en donde se observa el desarrollan suelos oscuros (b) Perfil de suelo descrito en la localidad del Triunfo, la escala métrica muestra una discontinuidad textural del perfil a $70 \mathrm{~cm}$ de profundidad, se identifican un aumento en proporción de sedimentos enriquecidos en limo (Martínez, 2015).

la disolución reciente de las rocas que la conforman y en algunos casos el control tectónico, finalmente el relleno es de material residual reciente (Figura 7).

XIII. Valle Fluvial: Esta unidad posee una morfología alargada, a lo largo del río Grande de Comitán y es el resultado de la dinámica fluvial del río (Figura 12).

La forma de la unidad se asocia a la ribera del río actual, evidencia el control estructural por las líneas de debilidad tectónica, sin embargo, el último tramo de la unidad no se acompaña por el río, lo que sugiere que el cambio de ruta es resultado de uno de los últimos eventos neotectónicos.

\section{Discusión}

La delimitación de las distintas unidades geomorfológicas del presente trabajo permite detallar a escala de cuenca las formas características y de manera preliminar, inferir la evolución y el comportamiento de la cuenca del Río Grande, Comitán.

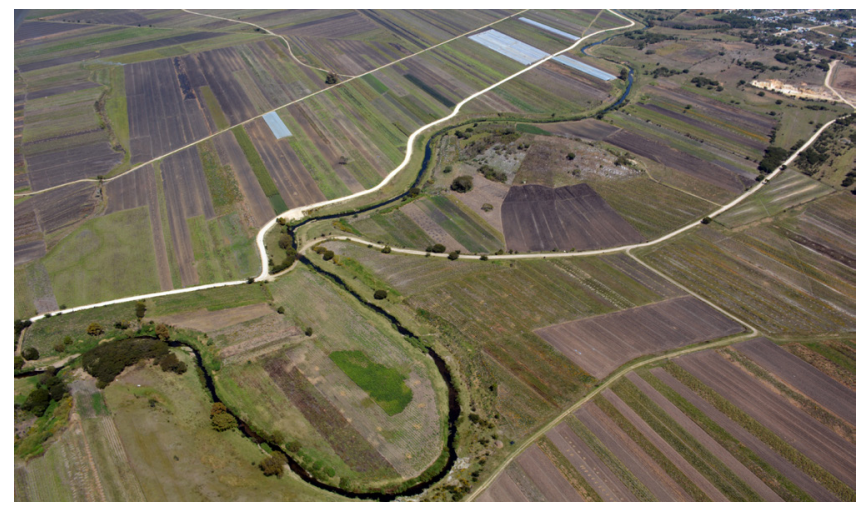

Figura 12 Ejemplo de la unidad XIII donde se observa el valle fluvial, con vegetación de galería en las márgenes de río.

Desde el punto de vista de las características analizadas, se reconoce un conjunto de morfologías con carácter principalmente kárstico, en el que coincide la presencia de rocas calizas y dolomías como principal factor litológico. En proporción relativa, la precipitación actual parece definir la morfología de las unidades de montaña, ya que la diferenciación entre las terrazas estructurales y el relieve mesiforme está marcada por el volumen de agua que recibe cada zona y la intensidad de disolución, 
en este sentido, las expresiones morfológicas son diferentes.

Desde el punto de vista de la evolución, la cuenca se comporta como un sistema kárstico evolucionado y polifásico, en el que se suman varios eventos que han reactivado diferentes áreas, por lo que su evolución es compleja y requiere estudios a mayor detalle.

A la escala de la cuenca, la presencia de abundantes sedimentos, tanto de piedemonte como de relleno en depresiones kársticas, también en unidades como planicies kársticas y planicies de acumulación lacustre, sugiere largos periodos de erosión-disolución en los que sedimentos y residuos insolubles han sido transportados y depositados en zonas de menor energía.

Por otro lado, la existencia de un área de llanuras de corrosión (Antigua planicie kárstica) con karst cónico relíctico, supone la existencia de procesos de larga temporalidad en los que la fase de ampliación horizontal supera las fases de profundización. Sin embargo, en algunas zonas se pueden observar procesos de reactivación asociados a posibles levantamientos recientes y que pueden ser exacerbados por cambios del uso del suelo. Asociado a los levantamientos tectónicos se propone la hipótesis de la existencia de un antiguo lago que fue desecado por cambio en el nivel de base local.

Otro aspecto importante en la cuenca es la presencia de depósitos conglomeráticos que contienen evaporitas. La unidad VIII sugiere la existencia de ciertos lagos bajos, tal vez residuales dentro del área de estudio. Aunque se desconoce la temporalidad y su estratigrafía a detalle, este tipo de lagos se pueden presentar en áreas en las que el nivel de base está muy cercano a la superficie, formando lagos con fondos planos. En esas condiciones, una reactivación tectónica reciente favorecería el descenso del nivel de base y con ello la evaporación y desaparición del mismo. Esta hipótesis permite explicar la formación de los depósitos con yesos y otras evaporitas. Una hipótesis alternativa puede estar asociada a cambios climáticos de nivel regio- nal. La alta tasa de erosión favorece el transporte superficial de material evaporítico hacia el inicio del sistema lacustre, que puede explicar parcialmente la movilidad de compuestos de azufre a los lagos.

De acuerdo a las expresiones morfológicas de la cuenca, las unidades I, II y III, correspondientes al relieve mesiforme con diferente grado de desarrollo, no tienen red de drenaje superficial, a pesar de la cantidad de agua de lluvia que recibe (aproximadamente $2500 \mathrm{~mm} / \mathrm{año}$ ) y la pendiente pronunciada de éstas. Esta es una evidencia de la alta infiltración del material a través de micro y macrofracturas asociadas a la evolución del karst. Este tipo de estructuras representan un riesgo ambiental ya que pueden infiltrar rápidamente compuestos provenientes de actividades asociadas al cambio de uso de suelo, no sólo de parte superficial, sino también de unidades contiguas.

Otros tipos de morfologías como las Terrazas estructurales y Mogotes, son formas que favorecen los procesos de erosión superficial debido a las pendientes que tienen y son las siguientes unidades más vulnerables en relación al transporte de material hacia el río o la base de la cuenca.

Finalmente, las unidades caracterizadas en el relieve de planicie (unidades IX, X, XI, XII y XIII) representan una cuenca favorecida por relleno de material residual. Estas morfologías se asocian a movilidad de material con baja energía, que no implican un gran riesgo para el cambio de la calidad del agua superficial. Sin embargo, el uso del suelo actual y el aporte de fertilizantes pudieran favorecer la eutrofización de los lagos.

\section{Conclusiones}

Este primer mapa geomorfológico desarrollado a partir de las herramientas morfométricas permitió establecer límites definidos de las diferentes unidades descritas, fundamentadas a partir de la altura, pendiente y rugosidad superficial. Además, de 
manera preliminar ponen en un contexto general, varias hipótesis de evolución del paisaje, con un enfoque aplicado al entendimiento del funcionamiento del sistema, como herramienta para el ordenamiento del territorio. Se identificaron trece unidades geomorfológicas agrupadas en morfologías de montaña, lomerío y planicie. Estas unidades se desarrollaron en litologías que comprenden calizas, dolomías, lutitas, conglomerados polimícticos y yeso.

Las unidades descritas sugieren diferentes etapas evolutivas del paisaje, por lo que hace complejo establecer la evolución del mismo. Se identifican unidades controladas por procesos de disolución-erosión y también reactivación debido a la dinámica estructural de la zona.

El comportamiento del sistema es complejo de tal forma que las unidades de montañas son las que pueden favorecer de manera superficial el movimiento de flujos de sedimentos y nutrientes hacia la base de la cuenca. Por otro lado, dado el desarrollo kárstico de estas unidades, y en particular las unidades de relieve mesiforme, favorecen el transporte interno e incrementan la carga de materiales y nutrientes hacia el sistema lacustre.

En este sentido, es importante ampliar el área de estudio, de tal manera que se incluyan áreas que puedan estar asociadas a los flujos internos, más allá del límite de la cuenca. De esta manera se pueden definir las áreas de recarga tanto autogénicas como alogénicas que pudieran afectar a los lagos a través de flujos subterráneos.

Por otro lado, se resalta la importancia de la unidad "Lomerío Bajo de Pendiente Continua y Denudatoria", la cual expresa características que implican alta movilidad de flujos externos como internos que favorecen la llegada de sedimentos y nutrientes a la base de los lagos aumentando la eutrofización de éstos.

Finalmente, este trabajo abre una ventana hacia el estudio de paisajes kársticos. En particular, en esta zona se requiere llevar a cabo trabajos a mayor detalle, para aclarar preguntas como la temporalidad de los eventos y aspectos estratigráficos del área.

\section{Software}

Los mapas generados en este trabajo se obtuvieron utilizando ArcGIS, Versión 10.1 Redlands, CA: Environmental Systems Research Institute, Inc., 2010. Usando licencia individual.

\section{Agradecimientos}

El presente trabajo se ha realizado en el contexto del desarrollo y apoyo económico del proyecto "Estudio hidrológico y de calidad del agua del Sistema Lagunar Montebello, Chiapas", del Fondo Sectorial CONAGUA-CONAGyT (167603). Al Dr. Lorenzo Vázquez Selem y al Dr. Mario Arturo Ortiz Pérez ${ }^{\dagger}$, por su apoyo en la interpretación de las unidades. A Francisco Hilario Bezerra y un revisor anónimo que permitieron mejorar la versión original de este trabajo.

\section{Referencias}

Arellano-Contreras, U., Jiménez-Salgado, E., 2011, Evaluación Geológico-Estructural del complejo volcánico el Chichonal, Chiapas, como fuente de energía alterna (resumen) en Memorias del XIX Congreso anual, Los Humeros Puebla, México, Asociación Geotérmica Mexicana, 23 p.

Comisión Federal de Electricidad (CFE), 2012, Estudio para conocer la calidad de agua de las Lagunas de Montebello, Chiapas, Tomo I, Hidrometeorología, Reporte Técnico. $264 \mathrm{p}$. 
Comisión Nacional de Áreas Naturales

Protegidas y Secretaría del Medio

Ambiente y Recursos Naturales (CONANP-

SEMARNAT), 2007, "Programa de

Conservación y Manejo Parque Nacional

Lagunas de Montebello, México",

disponible en <http://www.conanp.gob.mx/

que_hacemos/pdf/programas_manejo/

Final_Montebello.pdf>, consultado $18 \mathrm{de}$ noviembre de 2015.

Dikau, R.H., 1990, Geomorphic landform modelling based on Hierarchy Theorie en $4^{\text {th }}$ International, Symposium on Spatial Data Handling, 23rd-27 ${ }^{\text {th }}$ July, Zürich, 230-239.

Dikau, R.H., Brabb, E.E., Mark, R.K., Pike, R.J., 1995, Morphometric landform analysis of New Mexico: Zeitschrift fur Geomorphologie Supplementband, 101, 109-126.

Durán, G.J.I., 2013, Análisis geomorfológico del Parque Nacional Lagunas de Montebello, Chiapas: Ciudad de México, Universidad Nacional Autónoma de México, Tesis en Ingeniería Geológica, 88 p.

Durán, C.L., Escolero, O.F., Muñoz, E.FM., Castillo, M.C.S., Rodríguez, G.S.R., 2014, Cartografía geomorfológica a escala 1:50000 del Parque Nacional Lagunas de Montebello, Chiapas (México): Boletín de la Sociedad Geológica Mexicana, 66 (2), 263-277.

Espinasa-Pereña, R., 2007, El Karst de México. Mapa NA III 3, en Coll-Hurtado, A. (coord.), Nuevo Atlas Nacional de México: Instituto de Geografía, Universidad Nacional Autónoma de México.

Ford, D.C., Williams, P.W., 1989, Karst Geomorphology and Hydrology: Unwin Hyman, London, UK 601 p.

Ford, D.C., Williams, P.W., 2007, Karst

Hydrogeology and Geomorphology: John Wiley \& Sons, Ltd, Chichester, United Kingdom, 602 p.

Gallant, A.L., Brown, D.D., Hoffer, R.M., 2005,
Automated Mapping of Hammond's Landforms: IEEE Geoscience and Remote Sensing Letters 2 (4), 384-388.

Guzmán-Speziale, M., Meneses-Rocha, J.J., 2000, The North America-Caribbean plate boundary west of the Motagua-Polochic fault system: a fault jog in Southeastern Mexico: Journal of South American Earth Sciences, 13, 459-468.

Hammond, E.H., 1964, Analysis of properties in landform geography: An application to broad-scale land form mapping: Annals of the Association of American Geographers, 54, 11-19.

Instituto Municipal de Planeación de Comitán de Domínguez (IMPLAN Comitán), 2015, Plan de Gestión de la cuenca del Río Grande, Lagunas de Montebello, Chiapas, México, disponible en <http://www. implancomitan.org.mx/images/0_2\%20 MONTEBELLO\%20FINAL.pdf>, consultado 12 de enero 2015.

Instituto Nacional de Estadística Geografía e Informática (INEGI), 2007, Conjunto de datos vectoriales: Red Hidrológica escala 1:50000, Edición 2.0 Subcuenca RH30GI-R, disponible en < http://www. inegi.org.mx/geo/contenidos/recnat/ hidrologia/regiones_hidrograficas.aspx>, consultado 4 de febrero de 2014.

Instituto Nacional de Estadística, Geografía e Informática (INEGI), 2013, Continuo de elevaciones continentales 3.0, disponible en <http://www.inegi.org.mx/geo/ contenidos/datosrelieve/continental/ continuoelevaciones.aspx $>$, consultado $30 \mathrm{de}$ junio 2015.

Martínez, M.A., 2015, Caracterización de los suelos de la cuenca del Río grande, como soporte para entender la dinámica de contaminantes que llegan al sistema lagunar de Montebello, Chiapas: D.F., Universidad Nacional Autónoma de México, Tesis de Licenciatura en Biología, Facultad de Estudios Superiores Zaragoza, 102 p. 
Ortega-Gutiérrez, F., Mitre, S.L., Roldán, Q.J., Aranda, G.J.J., Morán, Z.D., Alaniz A.S., Nieto, S.A., 1992, Carta Geológica de la República Mexicana, 1:2000000: Washington, Williams \& Heintz (Mapa), Universidad Nacional Autónoma de México, Instituto de Geología, mapa con texto explicativo, $78 \mathrm{p}$.

Padilla-Sánchez, R.J., 2007, Evolución geológica del sureste mexicano desde el Mesozoico al presente en el contexto regional del Golfo de México: Boletín de la Sociedad Geológica Mexicana, Tomo LIX (1), 19-42. Quezada-Muñetón, J.M., 1987, El Cretácico Medio-superior, y el límite Cretácico superior-Terciario Inferior en la Sierra de Chiapas: Boletín de la Asociación Mexicana de Geólogos Petroleros, 34(1), 3-97.

Servicio Geológico Mexicano (SGM), 2013, Centro de documentación digital. Cartas, disponible en <http://mapserver.sgm.gob. $\mathrm{mx} /$ Cartas_Online/metadatos_geol>, consultado junio 25 de 2015.
Salas, G.R, 1949, El Cretácico de la Cuenca de Macuspana y su Correlación: Boletín de la Sociedad Geológica Mexicana, 14, 47-65. Stokes, T., Griffiths, P., Ramsey, C., 2010, Karst Geomorphology, Hydrology, and Management, en Pike, R.G., Redding, T.E., Moore, R.D., Winker, R.D., Bladon, K.D. (eds.), Compendium of forest hydrology and geomorphology in British Columbia. B.C, disponible en http://www.for.gov. bc.ca/hfd/pubs/Docs/Lmh/Lmh66.htm, consultado en 14 de noviembre de 2015.

Vázquez, M.A., Méndez, E., 1994, Aspectos generales de la región: Lagos de Montebello, Reporte del trabajo para el curso de conservación de naturaleza y recursos naturales, Maestría en Ciencias: Recursos Naturales y Desarrollo Rural, ECOSUR Chiapas.

Zinck, L.A., 2012, Geopedología, Elementos de geomorfología para estudios de suelos y de riesgos naturales: ITC Special Lecture Notes Series, primera edición 123 p. 